\title{
PRÓXIMOS OU SEPARADOS? \\ IDEIAS DE GIDDENS E BAUMAN SOBRE AS \\ MOTIVAÇÕES PARA A POLÍTICA
}

Luis Carlos Fridman

Anthony Giddens e Zygmunt Bauman diagnosticam tendências divergentes para a sociabilidade contemporânea, com implicações políticas igualmente díspares. Segundo Giddens, a democratização das emoções nas vivências intimas de indivíduos libertos das amarras tradicionais os habilita à "democratização da democracia". Para Bauman, $\mathrm{o}$ isolamento e a insegurança experimentados atualmente resultam no esfriamento geral das relações humanas por toda a parte e assim seres tementes com o que lhes reserva o futuro não se mostram dispostos a correr os riscos que a ação política solicita.

O relevo da discussão proposta por eles vincula a experiência cotidiana da vida privada com as motivações para a participação na esfera pública, em trajetos teóricos que se debruçam sobre a natureza das mudanças contemporâneas. No título, "próximos ou separados?" diz respeito às feições dos laços sociais nas atuais configurações institucionais, a serem examinadas em uma comparação crítica da obra dos autores.

A avaliação desses diagnósticos requer o acompanhamento das linhas de argumentação envolvendo os pontos centrais 
acerca do contorno e da dinâmica das instituições da modernidade "avançada" (Giddens) ou "líquida" (Bauman), base da caracterização da sociabilidade atual. As diferenças de nomenclatura serão incorporadas na discussão da natureza dos fenômenos abordados, em vez de figurar como demarcações prévias do contraste entre as obras. Inclusive porque eles mantêm um diálogo leal que ultrapassa suas divergências; Bauman leu e criticou os manuscritos de Modernidade e identidade (Giddens, 2002 [1999]), e Giddens contribuiu para a forma final de Modernidade e ambivalência (Bauman, 1999a [1991]), como figura nos agradecimentos do livro de Bauman. A análise e o contraste de suas ideias são mais importantes do que criar uma parada obrigatória em torno de títulos ou emblemas.

Anthony Giddens e Zygmunt Bauman partem de considerações históricas semelhantes, que remontam ao Iluminismo, para caracterizar a mentalidade moderna. Mas constroem argumentos diferenciados no desenvolvimento de seus estu242 dos, que recaem sobre as interpretações acerca da institucionalidade atual. Giddens ressalta a reflexividade e a radicalização das forças despertadas na Europa a partir do século XVII, que "ulteriormente se tornaram mais ou menos mundiais em sua influência" (Giddens, 1991, p. 11), com consequências sobre a intensidade e a velocidade das mudanças. Daí extrai a possibilidade de uma agenda positiva que carrega a pretensão de superar o neoliberalismo e os temas envelhecidos da esquerda. De seu lado, Bauman investiga o "inquieto espírito moderno" e avalia que a pretensão de "melhorar o mundo" resultou, nas atuais circunstâncias de mudança institucional, em um deslocamento dos temas de interesse público para a vida privada, com repercussões danosas sobre a aproximação entre os indivíduos.

Ambos partilham da concepção de que estamos sendo atingidos por fenômenos surpreendentes na maneira como a sociedade funciona. Rapidez, radicalização, velocidade, intensidade e alcance das mudanças denotam uma "descontinui- 
dade histórica" (Giddens, 1991, pp. 13 e 15), anotação que contém evidente parentesco com as observações de Bauman sobre os processos de estruturação contínuos em diversas dimensões da prática humana, raramente coordenados e submetidos a um plano abrangente ou a regularidades históricas. Em síntese ligeira, consideram que as feições institucionais da contemporaneidade denotam mecanismos que alteraram decisivamente as formas de vida e das relações humanas. Assim, as explicações e teorias dos autores não se limitam a conceitos históricos de alto teor de generalização ou, em uma caricatura, às acrobacias mais recentes de uma dinâmica capitalista que se acredita conhecer antecipadamente.

Apesar de prudente, Giddens não disfarça o seu otimismo quando estabelece nexos entre a democratização da vida privada e inclinações daí provenientes para a participação na cena pública. A reflexividade é a base da ampliação de limites e do dinamismo democratizante que politiza outras esferas da vida social, com consequências sobre a variedade de exercícios de poder. Giddens atribui à modernidade avançada afinidades evidentes com a democracia.

Mas as valiosas conquistas no plano da intimidade podem conviver com o imobilismo político ou, como adverte Zygmunt Bauman, com o desinteresse pelos outros, quando a "Política" (com P maiúsculo) se transfere para a "política da vida", campo onde vicejam as "utopias privatizadas", alimentadas incessantemente pelas promessas de felicidade ofertadas e consumidas no mercado. Apesar das mudanças proporcionadas pela "interrogação reflexiva do eu", as pontes entre as carências, sofrimentos e desejos da vida privada e sua expressão em demandas políticas de alcance geral são bloqueadas pela intensa privatização da esfera pública, algo que escapa à reflexão de Giddens. As pistas fornecidas por Bauman para o esclarecimento dessa ordem de questões parecem mais frutíferas que as projeções das motivações auspiciosas que são encontradas na reflexão de Giddens. 


\section{Anthony Giddens: destradicionalização e política da vida}

Segundo Giddens, as forças despertadas na modernidade estiveram imbricadas com o Iluminismo e com o elogio da Razão, combustível da mentalidade que acompanhou as mudanças econômicas, sociais, políticas e tecnológicas a partir de meados do século XVII e do século XVIII. Mas hoje, a magnitude desses impulsos ganhou novas proporções, por isso ele prefere definir os tempos que correm como "modernidade avançada" ou "modernidade radicalizada". Crescentemente "as práticas sociais são constantemente examinadas e reformadas à luz de informação renovada sobre estas próprias práticas, alterando assim constitutivamente seu caráter" e, portanto, "a revisão crônica das práticas sociais à luz do conhecimento sobre estas práticas é parte do próprio tecido das instituições modernas" (Giddens, 1991, pp. 45 e 47). Esses traços constitutivos da reflexividade estão na própria base da reprodução sistêmica, delineando novos 244 conteúdos e feições nas relações sociais.

Reflexividade diz respeito essencialmente à cognição dos atores sociais, isto é, à incorporação rotineira de conhecimento e de informação renovada que influi sobre o exame e a condução das práticas sociais. O conceito ressalta a importância decisiva das capacidades reflexivas do ator no fluxo da vida cotidiana. Dentro desses limites, Giddens confere à reflexividade atributos da mudança social. Porém, processos reflexivos não coincidem com a "tomada de consciência política" (referida à dominação econômica e à distribuição do poder). Tal confusão favorece, por vezes, algum açodamento crítico em relação à obra de Giddens - que certamente pode ser alvo de variadas objeções, inclusive de caráter político - pois desvaloriza o rendimento teórico do conceito.

Ao se avaliar a reflexividade somente a partir da ótica da ação política concertada e de narrativas encadeadas de crítica social, perde-se o que o conceito tem de mais precioso, 
que é a percepção da ação e do comportamento dos atores na vida cotidiana, o "seguir em frente", nas condições da modernidade radicalizada. A disseminação global de informações ou a sua incorporação nas rotinas não trazem o menu completo das relações sociais para as pessoas poderem degustá-lo como quiserem. O conceito não é prescritivo mas analítico, e nisso reside o seu valor.

A reflexividade atua nos níveis macro e micro da vida social. Uma das maneiras de se traduzir essa presença é a afirmação de que a atmosfera de "indagação racional permanente" confere uma dinâmica societária que deve ser investigada em todas as suas consequências. A intensificação das relações sociais pela globalização e pela destradicionalização influi sobre os fluxos econômicos, a tomada de decisões, o papel do Estado, o exercício do mando, as relações familiares, os vínculos hierárquicos entre os gêneros ou entre pais e filhos, a interrogação sobre o corpo e mesmo sobre a sexualidade. Produzem novas possibilidades de envolvimento dos indivíduos com aspirações que não se limitam às lutas por sanar ou mitigar as desigualdades de riqueza e poder.

Ainda no campo das macroestruturas e das microrrelações, Giddens observa contrastes entre a confiança depositada nos "sistemas peritos" (que não supõe mutualidade e intimidade) e as gratificações, também reflexivas, alcançadas na vida privada. Explicando melhor: sistemas peritos são "sistemas de excelência técnica ou competência profissional que organizam grandes áreas dos ambientes material e social em que vivemos" (Giddens, 1991, p. 35) e se poderia supor que nessas condições estariam reproduzidas, em grau ainda mais acentuado, as previsões de Max Weber da "gaiola de ferro" do processo de racionalização e as relações servis entre os atores sociais e burocracias. Mas a intervenção atribuída ao "sujeito reflexivo" é muito maior do que aquela reservada ao herói solitário no império burocrático. As questões 
existenciais da vida privada, devido às incorporações reflexivas, têm influência crescente sobre a agenda pública.

Anthony Giddens (1991, p. 126) revela uma postura preferencial pela "apropriação positiva das circunstâncias", derivada da análise da invasão das influências globalizadas na vida cotidiana. É o que se lê em Mundo em descontrole - o que a globalização está fazendo de nós quando afirma que "a globalização está por trás da expansão da democracia” (Giddens, 2000b, p. 16) através dos exemplos da derrocada do bloco soviético e das ditaduras no mundo inteiro. Apesar da atual descrença nos políticos, observa um incremento da cultura cívica e da fé nos processos democráticos que apontam para a "democratização da democracia" mesmo que as instituições da política ortodoxa sejam insuficientes para promovê-la. A destradicionalização, a reflexividade e a globalização atingem a vida privada e favorecem o que o autor chama de "democratização das emoções". Aí resi-

246 dem algumas pistas que ajudam a localizar suas ideias sobre o alcance das mudanças.

Na ótica de Giddens (1991, p. 142), o conceito de reflexividade refere-se a aspectos multidimensionais da ação, ou seja, a relação entre os atores e as estruturas não é marcada pelo "servilismo" dos primeiros e considera "um equívoco ver o mundo moderno como um mundo onde os grandes sistemas impessoais engolem crescentemente a maior parte da vida pessoal”. Ou ainda, como já havia antecipado em sua "teoria da estruturação" apresentada em A constituição da sociedade (Giddens, 1989, pp. XVIII e XIX), os limites exteriores não reduzem a capacidade de agir e instituir:

Os agentes ou atores humanos - uso indistintamente um e outro termo - têm, como aspecto inerente do que fazem, a capacidade de entender o que fazem enquanto o fazem. As capacidades reflexivas do ator humano estão 
caracteristicamente envolvidas, de modo contínuo, no fluxo da conduta cotidiana, nos contextos da atividade social. Mas a reflexividade opera apenas parcialmente num nível discursivo. O que os agentes sabem acerca do que fazem e de por que o fazem - sua cognoscitividade como agentes - está largamente contido na consciência prática (grifo do autor).

Tais pressupostos informam a análise da confiança na vida privada com atenção para os "relacionamentos", conceito que a princípio parece meramente descritivo ou carecer de conteúdo sociológico. Mas, olhando mais de perto, "relacionamentos" são tratados como vínculos positivos a partir de processos reflexivos "onde a confiança não é pré-dada mas trabalhada, e onde o trabalho envolvido significa um processo mútuo de autorrevelação". Neles é possível o reforço da confiança e a abertura do indivíduo para o outro e da descoberta de si. Daí se conclui que a "preocupação com a autossatisfação" é parte da "apropriação positiva de circunstâncias nas quais as influências globalizadas invadem a vida cotidiana”. Giddens não esconde seu entusiasmo prudente com a "transformação genuína da própria natureza do pessoal", fonte de possibilidades novas de autenticidade, sociabilidade e lealdade (Giddens, 1991, pp. 122, 123, 126; grifos do autor).

O conceito de "relacionamento puro" insinua a possibilidade da "democracia das emoções", o que transparece em outra definição como "um relacionamento de igualdade sexual e emocional, explosivo em suas conotações em relação às formas preexistentes do poder do sexo" (Giddens, 1993, p. 10). Mais extensamente:

Um relacionamento puro nada tem a ver com pureza sexual, sendo um conceito mais restritivo que descritivo. Refere-se a uma situação em que se entra em uma relação 
social apenas pela própria relação, pelo que pode ser derivado por cada pessoa da manutenção de uma associação com outra, e que só continua enquanto ambas as partes considerarem que extraem satisfações suficientes, para cada uma individualmente, para nela permanecerem. Para a maior parte da população sexualmente "normal", o amor costumava ser vinculado à sexualidade pelo casamento, mas agora os dois estão cada vez mais vinculados através do relacionamento puro. O casamento - para muitos, mas de forma alguma para todos os grupos da população - tem-se voltado cada vez mais para a forma de um relacionamento puro, com muitas outras consequências. Repetindo, o relacionamento puro é parte de uma reestruturação genérica da intimidade (Giddens, 1993, pp. 68-69).

O relacionamento puro traz o princípio da suspensão das hierarquias, o que não quer dizer que elas serão efeti248 vamente suspensas em todas as suas dimensões socialmente dadas. É um ponto de partida, ao invés de um ponto de chegada. Mas implica a democratização da vida pessoal e, no século XX, as mulheres tiveram um papel decisivo nesse rearranjo da vida privada. A intimidade, portanto, torna-se um campo de democratização, que envolve relações de igualdade emocional e sexual no casamento, na diversidade de vínculos de atração e afeto, nas formas de parentesco e amizade e nas relações entre pais e filhos. O relacionamento puro traz, em suas condições básicas, a proibição da violência, a negociação de um "contrato móvel" (e, portanto, passível de desistência de uma das partes segundo o padrão da autonomia) e o compromisso segundo as necessidades e o grau de satisfação de cada parceiro na relação. Supõe a determinação dialogal das condições da própria associação e uma comunicação livre e aberta. Trata-se na verdade de um tipo-ideal, com o qual Giddens (1993, p. 206) trabalha conscientemente quando 
afirma que "a distância entre os ideais e a realidade é considerável”, atenuado logo a seguir pela aceitação de que "as mudanças que ajudaram a transformar os ambientes da ação pessoal já estão bem avançadas, tendendo para a realização das qualidades democráticas”.

Essas mudanças suscitam em Giddens a formulação de seu "realismo utópico", ou seja, algo que não existe em seus contornos plenos, mas já se anuncia como tendência em vista do "projeto reflexivo do eu" nas sociedades modernas. Impele à "colonização do futuro" pela inauguração de um universo de ação social e de experiência verdadeiramente novo. Compõe-se dos aspectos já presentes e constatados da transformação da intimidade e da abertura para o outro como incremento da solidariedade social e aponta para a possibilidade de uma "conversa cosmopolita do gênero humano", imagem prospectiva de Richard Rorty mencionada no artigo "A vida em uma sociedade pós-tradicional" (Giddens, 1997, p. 123).

A transformação da intimidade (título de um dos livros de Giddens [1993]) gera, em seu sentido último, uma subjetividade marcada pela disposição de autonomia emocional que acaba por fazer emergir na agenda pública temas anteriormente restritos à esfera privada. Esse povoamento do espaço público é extremamente relevante para Giddens, algo como uma derivação política da dinâmica societária da modernidade avançada. Ele se defende da pecha de "idealista" ao enfatizar que nos últimos cem anos aconteceram mais mudanças nas relações entre homens e mulheres (ou no cenário que abrange a sala, o quarto, a cozinha e o banheiro) do que aquelas alcançadas por longas séries de gerações.

$\mathrm{O}$ que ocorreu em ambientes privados e alcançou a esfera pública também informa a possibilidade de uma "cidadania reflexiva em um mundo globalizador" (Giddens, 1996, p. 18), que solicita mais do que um sistema partidário- 
eleitoral para ser exercida. Este é um mundo que, para além das lutas para suplantar as privações materiais e as desigualdades de poder e de riqueza - a "política emancipatória" -, expande a "política da vida", cujo foco não se restringe às "oportunidades de vida" e avança sobre a diversidade dos estilos de vida.

Cada termo da síntese conceitual "política da emancipação + política da vida" merece maior detalhamento. Política emancipatória refere-se a "engajamentos radicais voltados para a liberação das desigualdades e da servidão (envolvendo "modelos da sociedade boa')" e a política da vida como "engajamentos radicais que procuram incrementar as possibilidades de uma vida realizada e satisfatória para todos e para qual não existem 'outros' (envolvendo decisivamente uma 'ética do pessoal' e a política referida a estilos de vida)" (Giddens, 1991, pp. 155, 156).

Uma "ética do pessoal", proveniente de vínculos afetivos 250 e sexuais, está presente em variadas dimensões da experiência humana na modernidade avançada e pode ser incluída entre as características básicas da política da vida (cf. Giddens, 1991, p. 156). Com destaque para a destradicionalização da família, cujos laços estão sendo profundamente modificados. Anteriormente não se observava "o nível de intimidade que associamos às relações pessoais e sexuais hoje em dia” (Giddens, 1991, p. 143).

Nessa concepção, estão presentes considerações "realistas" acerca das desigualdades com antecipações "utópicas", que repõem a questão aristotélica, ética, "que vida quero viver?" (Giddens, 1993, p. 292), revisitada por Amartya Sen (1992) em "Comportamento econômico e sentimentos morais". A política da vida é a política da autorrealização, sem adiamentos para o hipotético futuro, despertada no ambiente institucional da modernidade avançada. Também carrega a recordação dos anúncios de Theodore Rozsak, na década de 1960, que proclamava o caráter subversivo da busca de iden- 
tidade pessoal. Giddens reconhece em suas ideias a influência da obra de Herbert Marcuse, um destacado inspirador intelectual da "grande recusa" na década de todas as revoltas. Marcuse (1979, p. 51) escrevia arrebatado em A ideologia da sociedade industrial: o homem unidimensional: "em última análise, a luta por uma expansão do mundo da beleza, da não violência, da calma, é uma luta política”. Giddens busca conservar o sentido dessas palavras como indicativo da "política de autorrealização", porém com conotações políticas adequadas às mudanças institucionais ocorridas desde então.

A referência a Marx é óbvia, para quem a autorrealização era um objetivo a ser alcançado no futuro, quando os homens tivessem superado as desigualdades materiais dos regimes de propriedade privada dos meios de produção e ultrapassado a fixação a uma esfera exclusiva de atividade, como se lê na clássica passagem de A ideologia alemã. Nas antevisões de Marx, seria um cenário no qual cada um poderia expandir livremente as suas potencialidades, se assim o desejasse.

Para Giddens, além das óbvias discordâncias com a filosofia da história marxista, tal sucessão foi rompida pela ética do pessoal, referida à política da vida (de igual importância aos ideais de justiça e igualdade), que antecipou a busca de autorrealização ${ }^{1}$. Com isso, as possibilidades de subversão estenderam-se a outras esferas do mundo da vida, lembrando o conceito que percorre a obra de Jürgen Habermas. Não é demais repetir que o conceito de "política da vida" informa as motivações para a ação política e as concepções sobre a "democracia das emoções". Giddens opera uma reflexão dos processos em curso na modernidade avançada, explorando teoricamente o que eles podem apontar para o

1 Também discuto a "antecipação" de demandas de autorrealização em O jardim de Marx - comunismo e teoria social contemporânea (Rio de Janeiro, Relume Dumará, 2003). 
futuro. Supõe assim uma convergência dessa dinâmica institucional com a "democratização da democracia"2.

A política da vida e a democratização das emoções estão relacionadas à política gerativa, aquela em que indivíduos e grupos fazem as coisas acontecerem (Giddens, 1996, pp. 23 e 24). A presença de demandas existenciais na esfera pública, que ultrapassa os padrões usuais de atuação dos partidos políticos, denota as suas origens.

Os indivíduos que têm um bom entendimento de sua própria constituição emocional, e que são capazes de se comunicar de maneira eficiente com os outros em sua base pessoal, provavelmente estão bem preparados para as tarefas e responsabilidades mais amplas da cidadania (Giddens, 1996, p. 25).

No artigo "A vida em uma sociedade pós-tradicional", 252 anteriormente mencionado, Giddens (1997) defende a ideia de que há uma simetria real e clara entre a possibilidade de uma "democracia das emoções" no âmbito da vida pessoal e o potencial para a democracia no âmbito da ordem global. Concebe que a destradicionalização da sexualidade, do amor, do casamento, das relações entre os gêneros, além da comunicação aberta, dos vínculos negociados reflexivamente e a igualdade sexual e emocional aumentam as chances de relações mais solidárias, dialógicas, e fazem avançar processos democráticos de longo alcance. O diagnóstico da "apropriação positiva das circunstâncias" na modernidade avançada sugere a possibilidade de laços mais auspiciosos e de uma vida melhor. Giddens projeta que "as questões da política-vida provavelmente assumirão cada vez maior importância nas arenas públicas e jurídicas dos Estados" (Giddens, 2002 [1999], p. 208).

\footnotetext{
${ }^{2}$ Giddens (1991) desenvolve seus argumentos sobre o assunto no capítulo "Conduzindo o carro de Jagrená", de As consequências da modernidade. Ver também Fridman (2000), capítulo "Vertigens pós-modernas - a subjetividade contemporânea".
} 
A afinidade dos trajetos reflexivos com processos de autorreconhecimento inclina Giddens a tratar Freud como um autor debruçado sobre a destradicionalização das relações familiares, sem incluir em sua sociologia os rendimentos da investigação sobre o inconsciente e sua incidência sobre os conflitos e atordoamentos observados socialmente ${ }^{3}$. Mesmo que a démarche teórica seja pontual, circunscrever Freud à destradicionalização não robustece a eficiência das ideias em torno da "política de autorrealização" no esclarecimento das disputas políticas contemporâneas. E, quanto à interpelação do poder, Giddens não explora as diferenças marcantes, para a "política da vida", entre o vigor da contestação generalizada dos anos 1960 e a superação das hierarquias em ambientes privados na atualidade.

No capítulo final de A transformação da intimidade, Giddens retoma a simetria entre a "democratização das emoções” e a democratização política, que consiste na percepção de uma série de mecanismos análogos ou correlatos entre a suspensão das hierarquias na vida íntima e as regras que orientam a vida democrática. As "relações livres e iguais" entre os indivíduos guardariam elementos comuns com uma ordem democrática, baseadas na autonomia, na determinação das condições de sua associação e na proteção contra o uso arbitrário da coerção, entre outros. A "intimidade democrática" aponta para a democratização na esfera pública não no sentido de sua politização estrita, mas de uma "remoralização" das escolhas de vida (Giddens, 1993, p. 215).

Mas o olhar de Giddens nessa direção deixa descoberto o fato de que o conservadorismo político assimilou as demandas existenciais da destradicionalização e do "projeto reflexivo do eu". Hoje as conquistas da revolução sexual dos

\footnotetext{
${ }^{3}$ A esse respeito, ver as elaborações da psicanalista francesa Elizabeth Roudinesco (2010), em Retorno à questão judaica, acerca das manifestações do inconsciente nos discursos sociais.
} 
anos 1960 e a pregação de Rozsak do caráter subversivo da busca de identidade pessoal ganharam versões que apresentam mesclas variadas de desejos liberados com valores que reproduzem relações de poder e deixam intocados mecanismos que reforçam novos afastamentos e submissões.

No convívio social da "política da vida", nem sempre se confirma que indivíduos que têm um bom entendimento de sua constituição emocional estão mais preparados para a cidadania e para a "democratização da democracia". Os tipos ideais do "projeto reflexivo do eu" ou do "relacionamento puro" também podem conter a indiferença dos vencedores. Essa "ética do pessoal” pode funcionar auspiciosamente em um dado círculo de relações e simplesmente não levar em conta o destino dos demais em convivência democrática. Ao lado dos avanços do autoquestionamento e da descoberta de si envolvidos diretamente com a reflexividade contemporânea, é necessário considerar que as 254 formas moleculares de poder ou mesmo as aberrações ideológicas não retroagem necessariamente com a difusão da "política da vida".

A boa "constituição emocional" não resulta necessariamente em maior habilitação às tarefas e responsabilidades democráticas. Distorções restam intocadas mesmo entre pessoas dispostas à "abertura para o outro" ou que buscam autenticidade, autorrevelação e autossatisfação. O "relacionamento puro" - tipo ideal compatível com a destradicionalização - parece ocupar uma região a salvo das motivações inconscientes, onde os propósitos explicitados nem sempre traduzem as forças que emanam dessa zona obscura.

Richard Sennett (1999) chamou de "intercâmbio destrutivo" o despejo no outro de todos os "segredos" e "verdades" em nome da autenticidade. Coloca em dúvida que palavras e confissões assim divididas, custe o que custar, correspondam aos mais sinceros desejos de igualdade emocional. A autonomia associada a essa teoria da exposição permanente 
das entranhas lança sobre os ombros do parceiro uma responsabilidade difícil de suportar, pois nem tudo declarado "autenticamente" por alguém pode ser compensado satisfatoriamente pelo outro.

A complexidade do envolvimento emocional apresenta precariedades, imperfeições de toda ordem e insatisfações que podem não ser de todo resolvidas e, no entanto, sobreviverem ao compromisso amoroso. A intimidade é carregada de ambivalência, silêncios, coisas não ditas, sentimentos nem sempre claros entre os parceiros, motivações inconscientes de deciframento trabalhoso e mesmo inalcançável. Isso tudo não a desmerece e é inútil buscar compensações para essa condição humana. Assim, no emaranhado ambivalente das situações afetivas, nem sempre é possível associar o "relacionamento puro" à "democracia das emoções".

O valor das ideias de Giddens sobre a "política da vida" reside na politização de questões existenciais que não faziam parte do debate público, contribuindo para a formação de correntes de opinião e de disputa pela afirmação da diversidade dos estilos de vida. Algo que, sem dúvida, livra enormes contingentes humanos de repressões e sanções sociais, além de sua incorporação à cidadania. Mas não fica evidente que a democratização das emoções possui simetria com a "democratização da democracia".

\section{Zygmunt Bauman: desengajamento, identikits e desinteresse pelos outros}

Zygmunt Bauman aprecia as fundações da modernidade atento aos mesmos fenômenos que se tornaram objeto da reflexão de Anthony Giddens, ou seja, os impulsos fornecidos pela utilização da razão para ordenar, planejar e conferir um rumo desejável sobre a ordem das coisas. O destino declarado do espírito moderno era o de se debruçar sobre a natureza, a sociedade e o próprio indivíduo e proporcionar uma vida satisfatória para todos. 
Com o Iluminismo, o futuro - e não mais o destino inexorável - passou a ser concebido como território a ser conquistado, o que imprimiu um dinamismo veloz e assombroso em contraste com o mundo social até então ancorado na tradição, na comunidade, nas relações de parentesco e na religião. A construção da ordem passou a ser concebida como tarefa humana.

A partir de meados do século XVII, as forças despertadas na Europa alteraram profundamente as formas de vida e de organização social baseadas no aconchego dos costumes cristalizados ou das orientações em que o passado tinha uma pesada influência sobre o presente. Em vez do "eterno retorno" às revelações do passado, inaugurava-se a expectativa de um novo começo e da continuação ininterrupta de novas coisas pela posse das chaves do conhecimento que porventura permitiriam aos homens abraçar o mundo e transformá-lo segundo seus desígnios conscientes. Segundo Bauman, esse foi o sonho de legislar 256 racionalmente sobre a diversidade das coisas do mundo.

A pretensão racional e ordenadora orientou a constituição do Estado moderno e inflou o entusiasmo por uma vida coletiva racionalmente administrada. As possibilidades abertas pelo advento das burocracias facilitaram o esquadrinhamento dos problemas e potencialidades em todas as esferas sociais. Tudo isso estava impregnado da certeza em suas consequências benéficas para os grandes grupos humanos. Visando eliminar o acaso e a contingência - essas "impurezas" que a vida referida ao passado e ao destino inexorável creditado à divindade conservava -, procedeu-se à institucionalização do "Estado jardineiro" (Bauman, 1999a, p. 29), onde a "suprema e inquestionável autoridade da Razão" serviu para separar as plantas úteis das ervas daninhas. A construção da ordem ganhava novos princípios.

\footnotetext{
4 A esse respeito, ver Bauman (1999a), capítulo I, "O escândalo da ambivalência”, de Modernidade e ambivalência.
} 
Um mundo ordeiro é aquele em que sabemos como prosseguir, ou (incluindo a razão e o planejamento para rechear essa engenharia social) aquele

[...] no qual sabemos como calcular a probabilidade de um evento e como aumentar ou diminuir tal probabilidade; um mundo no qual as ligações entre certas situações e a eficiência de certas ações permanecem no geral constantes, de forma que podemos nos basear em sucessos passados como guias para outros futuros (Bauman, 1999a, p. 10).

Esse esforço racionalizador (ou ordem a ser permanentemente refeita, ampliada ou concluída através da razão legislativa) foi acompanhado da ideologia do progresso, inflamada pela combinação entre a transparência do mundo e projetos históricos emancipadores das imperfeições. Mas a tarefa humana de construção da ordem pela razão legislativa não ofereceu as garantias últimas de uma vida para sempre serenada de todas as impurezas, contingências e da sombra da imprevisibilidade.

O espírito moderno também estava presente no Manifesto comunista de Karl Marx e Friedrich Engels, que trazia uma enfática descrição da superação pelo capitalismo das "relações ossificadas", analisado por Marshall Berman no ensaio "Tudo que é sólido desmancha no ar". O capitalismo derretia a vida tradicional e ampliava as fronteiras das realizações humanas pela "vida ativa" - a transformação de sonhos e fantasias em realidades, proporcionadas pelo espantoso desenvolvimento material do sistema emergente (Berman, 1986, p. 91) - e pela busca permanente do novo. Essa ordem instalava-se pela sublevação de todas as relações tradicionais, exibida na irresistível e brutal expansão econômica, nos avanços da ciência aplicada à produção material, na crença no lado radiante desse "progresso" e no orgulho por essas façanhas. No exame do Manifesto, 
Bauman sugere que a mentalidade que impelia à mudança dizia respeito

[...] ao tratamento que o autoconfiante e exuberante espírito moderno dava à sociedade, que considerava estagnada demais para seu gosto e resistente demais para mudar e amoldar-se a suas ambições - porque congelada em seus caminhos habituais (Bauman, 2001, p. 9).

Outra vertente da mesma interpretação é encontrada na seguinte passagem de Modernidade e ambivalência:

A modernidade é o que é - uma obsessiva marcha adiante - não porque queira sempre mais, mas porque nunca consegue o bastante [...] A marcha deve seguir adiante porque qualquer ponto de chegada não passa de uma estação temporária. Nenhum lugar é privilegiado, nenhum melhor do que outro, como também a partir de nenhum lugar o horizonte é mais próximo do que de qualquer outro (Bauman, 1999a, p. 18).

A moldagem de uma "sociedade boa" pressupunha a intervenção sobre as instituições de maneira a reformá-las nesse contínuo aperfeiçoamento do mundo. O sonho do "legislador absoluto", armado da Razão que ultrapassava a experiência vulgar e revelaria a verdade, foi acompanhado das aspirações de harmonia social, felicidade e de um mundo finalmente serenado.

A pretensão modeladora embalava as iniciativas saneadoras das "imperfeições" da sociedade e do Estado. Marx e Engels, filhos do Iluminismo, acrescentaram que a razão histórica estaria encarnada nos grandes agregados de indivíduos submetidos à dominação na produção da riqueza material: os trabalhadores enquanto classe social. Sua emancipação e o alívio de seus sofrimentos pressupunham 
um melhoramento do mundo pela revolução, pela transformação das relações existentes. A moldura de classe passou a condensar as condições de movimentação humana segundo estratégias e projetos definidos pela junção das dores, ou seja, pela identificação dos padecimentos comuns. O "casamento às turras" entre o capital e o trabalho (uma imagem de Bauman para a luta de classes e para o conflito insolúvel, porém engajado, entre os partícipes fundamentais da ordem moderna) produzia vínculos imediatos entre a vida privada e as disputas públicas.

Mas agora vivemos o tempo do colapso do Estado como um dos campos privilegiados do "conserto do mundo", com o sacrifício dos ideais de "sociedade boa" e "sociedade justa". Isto quer dizer que a nova forma da modernidade é extremamente individualizante e fragmentadora da experiência. Na estrada que liga a vida privada à vida pública não se pode contar tanto com os outros na busca da "vida boa". Em termos sociais, a felicidade, ou o alívio das dores, devem ser buscados individualmente com os recursos que porventura se tiver à mão.

Margaret Thatcher pronunciou o epitáfio do Estado associado ao melhoramento do mundo quando disse "não existe essa coisa chamada sociedade" (Bauman, 2000, p. 75). O que existe são indivíduos e famílias na sua liberdade de escolher formas de vida segundo os meios amealhados em dadas condições para o cumprimento de objetivos intransferíveis. Segundo tal concepção, a liberdade é a liberdade de cada um, descartada qualquer interferência supraindividual como o Estado, a coletividade ou a política. São ideias que aplainam o terreno para a implantação dos projetos de plena desregulamentação e de trânsito desimpedido para as forças do mercado.

Para Anthony Giddens (2000a), Margaret Thatcher não foi uma conservadora comum, tendo sido objeto de reflexão em seu livro A terceira via - reflexões sobre o impasse político 
atual e o futuro da social-democracia. A "Dama de Ferro", sob a bandeira do livre-mercado, sacudiu as instituições existentes e implementou a liberação de forças que já provocavam mudanças na vida social contemporânea. Giddens percebe claramente os danos dessa orientação, no entanto destaca que é necessário dar o salto para além dessas mudanças em vez de retornar ao "velho estilo" das concepções da esquerda que não mais dão conta das novas realidades.

$\mathrm{O}$ acerto de contas de Giddens com o neoliberalismo, personificado em Margaret Thatcher, significou resgatar para a social-democracia as ações e os temas que nas últimas décadas foram conduzidos pela direita. A ideia da "terceira via" se refere a uma estrutura de pensamento e de prática política que visa adaptar a social-democracia a um mundo que se transformou fundamentalmente ao longo das últimas décadas. "É uma terceira via no sentido de que é uma tentativa de transcender tanto a social-democracia do velho 260 estilo quanto o neoliberalismo" (Giddens, 2000a, p. 36). Estas palavras foram escritas em 1998.

Para além da agenda positiva suposta por Giddens, Bauman percebe outras consequências na mudança. A privatização dos problemas esvazia a esfera pública das questões que absorveriam as aflições comuns e coletivas dos "cidadãos interessados" (Bauman, 2001, p. 49). O estímulo do aperfeiçoamento, próprio do espírito moderno, é deslocado da Política (com $\mathrm{P}$ maiúsculo), isto é, das tarefas maiores de moldagem das instituições sociais e do Estado, para a vida privada. Operou-se um deslocamento das "causas comuns" para a autoafirmação do indivíduo, cujo conjunto de tarefas está associado ao conceito de "política da vida". A "velha ordem defeituosa" (Bauman, 2001, p. 12), cujo aprimoramento demanda forças mais que individuais, deixou de ser o tema central da agenda política pela erosão dos elos que vinculam as escolhas individuais em projetos coletivos. 
Os traços do inquieto espírito moderno são trasladados da agenda política e pública para os esforços rotineiros de "ficar de pé" ou nas versões variadas do que pode significar a "felicidade pessoal" em uma era de individualização extremada. Em outra alusão ao Manifesto comunista, Bauman (2001, p. 14) vê profundas diferenças entre o momento atual da modernidade ("líquida") e aquele em que Marx e Engels produziram a célebre expressão e ao diagnóstico enfaticamente moderno de "tudo que é sólido desmancha no ar": "Os poderes que liquefazem passaram do 'sistema' para a 'sociedade', da 'política' para as 'políticas da vida' - ou desceram do nível 'macro' para o nível 'micro' do convívio social". Completando o diagnóstico, define o que está sendo desmanchado ou "derretido": "Chegou a vez da liquefação dos padrões de dependência e interação".

A obra de Bauman nas últimas décadas é um vasto programa de estudos e pesquisas orientado pela hipótese de que vivemos em uma era de desengajamento. $\mathrm{O}$ distanciamento e a indiferença afetam as relações nas diversas esferas sociais, como trabalho, finanças, política, a condução da vida cotidiana e as feições da subjetividade. Seus livros partem da consideração geral de que o desmantelamento do Welfare State e das redes de proteção social contém a declaração política de que a sociedade não mais se imiscui no infortúnio das parcelas da população atingidas pelas desigualdades da "globalização negativa" e pela "economia política da incerteza", definida como "o conjunto de "regras para pôr fim a todas as regras', imposto pelos poderes financeiros, capital e comercial extraterritoriais sobre as autoridades políticas locais" (Bauman, 2000, p. 175).

Daí advém uma mentalidade nefasta de que a busca da resolução dos problemas individuais e da felicidade deve ser conduzida apesar dos outros, contraste acentuado com largos períodos de tempo do século XX em que a associação entre os indivíduos era um elemento indispensável 
nessa busca. Ou ainda, como Bauman (2001, p. 42) sugere em Modernidade líquida, "as privações se somavam, por assim dizer; e, uma vez somadas, congelavam-se em 'interesses comuns' e eram vistas como tratáveis apenas com um remédio coletivo".

Daí se segue que em lugar de destacar o caráter positivo da destradicionalização e seu impacto sobre as relações sociais, Bauman repete em seus escritos uma palavra em alemão, Unsichercheit, que funde as experiências de insegurança, incerteza e falta de garantias (cf. Bauman, 2000, p. 13), arcabouço do esfriamento geral das relações humanas por toda parte (cf. Bauman, 2000, p. 60). Assim, seres tementes e assustados com o que lhes pode acontecer tendem a não correr os riscos da ação política, interrompendo as vias de ligação entre os problemas individuais e os temas públicos. Nesse sentido, há mais abstinência e indiferença em relação à mobilização de grupos e classes do que 262 "democratização da democracia”. A "Política (com p maiúsculo)", segundo Bauman, cede lugar a uma "política da vida" com um significado diferente daquele atribuído por Giddens, entendida desta vez como a região dos esforços segundo recursos e meios individuais para o enfrentamento das precariedades. Ou ainda, como o terreno de soluções biográficas para contradições sistêmicas.

As ideias de Bauman encontram eco nas pesquisas de Richard Sennett, com o foco nas relações de trabalho. Para o sociólogo norte-americano, essa é uma era da "força dos laços fracos" (Sennett, 1999, p. 25), onde isolamento e a fragmentação como condição social e existencial dos indivíduos fazem parte da nova estruturação sistêmica. Sennett examina o declínio das relações "sólidas", como lealdade, confiança, solidariedade e compromisso mútuo entre os trabalhadores, que só se robustecem no tempo e no convívio duradouro. A isso confere o título de "a corrosão do caráter", experimentada na reorganização produtiva do capitalismo da especialização flexível. 
Os trabalhadores são realocados com frequência em novas equipes e "projetos" e "pede-se que sejam ágeis, estejam abertos a mudanças de curto prazo, assumam riscos continuamente, dependam cada vez menos de leis e procedimentos formais" (Sennett, 1999, p. 9). Além do emprego se tornar algo contingente, a ideia de carreira se desvanece. $\mathrm{O}$ companheirismo no trabalho carece de tempo para se consolidar e o ambiente institucional não favorece a criação de laços fortes entre os indivíduos. A produção material assim reorganizada traz uma nova experiência do tempo - "não há longo prazo" (Sennett, 1999, p. 21) -, que transborda para outros domínios, entre eles a vida familiar e emocional.

Essa dinâmica institucional faz da dependência "uma condição vergonhosa" (Sennett, 1999, p. 166) e pessoas passivas são tomadas pelo sentimento de culpa, exceto aqueles que se ambientaram confortavelmente nos vínculos "líquidos". O "projeto reflexivo do eu" não estende seu manto de forma tão protetora a ponto de neutralizar os danos e os ônus da fragilização dos laços. A dissipação progressiva da dependência por indivíduos reflexivos que têm bom entendimento de sua constituição emocional parece mais um ideal de ego (que pode ser interpretado como compensação psíquica ao desmantelamento das redes de proteção social) do que uma experiência socialmente disseminada. Essa porta está aberta para alguns e indubitavelmente fechada para a maioria; seria adentrada apenas pelos portadores do cosmopolitismo dos bem-sucedidos.

Diferente de Giddens, que vê no lado auspicioso da modernidade avançada as possibilidades de uma vida mais autônoma e a politização da esfera pública com demandas de autorrealização, Bauman e Sennett se debruçam sobre os mecanismos de afastamento dos indivíduos entre si. Ao contrário da "democratização da vida privada" e suas consequências positivas nos demais planos da vida social, reparam situações de insegurança e deriva. 
O sofrimento ou a tentativa de sua atenuação no processo de autoconstrução individual lança os indivíduos em outra direção, a da aquisição de "maneiras de ser". Empenhar-se em relações duradouras, cujas compensações no presente e no futuro implicam graus variados de frustração, pode ser evitado ou contornado por serviços contratados. Esta é a origem do conceito de "identikit" formulado por Bauman (1999a, pp. 216-17) em Modernidade e ambivalência:

O mercado põe à disposição uma ampla gama de "identidades", das quais pode-se escolher uma. Os reclames comerciais se esforçam em mostrar em seu contexto social as mercadorias que tentam vender, isto é, como parte de um estilo de vida especial, de modo que o consumidor em perspectiva possa conscientemente adquirir símbolos da autoidentidade que gostaria de possuir. O mercado também oferece instrumentos para "construir identidade", que podem ser usados diferencialmente, isto é, que produzem resultados algo diferentes uns dos outros e que são assim "personalizados", feitos "sob medida", melhor atendendo às exigências da individualidade. Através do mercado, podemse colocar juntos vários elementos do "identikit" completo de um eu. A mulher pode aprender como se expressar de forma moderna, liberada, desembaraçada ou como uma dona de casa razoável, séria, cuidadosa; pode-se aprender a ser um magnata impiedoso, autoconfiante, empreendedor, ou um camarada amável, calmo, ou um macho de físico exuberante, ou uma criatura sonhadora, romântica, sedenta de amor - ou qualquer mistura de algumas ou todas essas imagens [...] A incerteza quanto à viabilidade da identidade autoconstruída e a agonia de procurar confirmação são assim evitadas (grifos do autor).

É possível comprar "maneiras de ser", kits de identidade feitos "sob medida". O mercado mostra-se plenamente 
preparado para saciar essas demandas e oferecer uma gama constantemente renovada de produtos para a "autoconstrução”. Em O mal-estar da pós-modernidade, Bauman (1998, p. 36) nomeia esse processo de "identidade de palimpsesto", onde é mais importante esquecer do que lembrar. A narrativa inescapável e intransferível do ser, pelo cumprimento do trajeto de vida, tem suas dores amenizadas pela aquisição de "mercadorias de ser", neutralizando suas agonias.

Pode-se comprar o acesso à sensação de se ter 1 milhão de amigos em redes sociais ou produtos que garantem o "estar conectado" como índice de uma vida fluente e cheia de novidades. Ou mesmo os serviços de modelagem de corpos como passaporte à suposta perfeição que garante todos os gozos. Os exemplos são inumeráveis e há especialistas e produtos para cada desconforto de alma.

A privatização não ocorre apenas no nível macro da sociedade, ela afeta diretamente as orientações da vida individual. A "modernidade líquida" (que Bauman chamou anteriormente de "pós-modernidade" e depois abandonou por considerar infrutíferos os debates semânticos) apresenta um estado permanente de pressão para despojar o destino individual de toda interferência coletiva. Nada favorece o valor de vidas cultivadas na companhia dos outros. Os indivíduos se tornam administradores solitários de suas dificuldades e aspirações, com a erosão das referências que permitiam a agregação dos sofrimentos privados e sua expressão em temas comuns, objeto de luta e negociação política na esfera pública.

Enquanto Giddens vincula o processo de globalização e a "política da vida" aos dividendos auspiciosos da destradicionalização, Bauman relaciona a "política da vida" à "globalização negativa" e à "economia política da incerteza”, seletivas e desiguais, que compreendem o desmantelamento das redes de proteção social e resultam na insegurança generalizada. Daí a "política da vida" ser marcada pelos esforços individuais de enfrentar as dores e sofrimentos com meios 
e recursos despojados de garantias institucionais. Em vez de a esfera pública ser colonizada por demandas de autorrealização instigadas pela democratização das emoções, o que se assiste é o povoamento do espaço público por preocupações particularizadas.

Nesse processo, os indivíduos se veem defrontados com todo tipo de aconselhamento nos meios de comunicação de massa, com o prestígio crescente de especialistas que pontificam sobre cada problema existencial - os "personal tudo" -, ou ainda com a exposição da vida das celebridades como exemplos a serem imitados no mar das atribulações cotidianas. Há também os programas de televisão "confessionais", os talk shows dos mais variados tipos e, dependendo do público a que se destinam, contam com a presença de famosos ou anônimos que vomitam seus problemas íntimos a serem "elaborados" por milhões de espectadores que dão tratos à bola para não se meterem 266 nos mesmos fracassos e embrulhadas.

No quadro da privatização intensa da esfera pública, Bauman (2001, pp. 38-39) opera uma distinção importante entre "líderes" e "conselheiros", para dar conta dos agentes que circulam nesse ambiente social.

Não mais grandes líderes para lhe dizer o que fazer e aliviá-lo da responsabilidade pela consequência de seus atos; no mundo dos indivíduos há apenas outros indivíduos cujo exemplo seguir na condução das tarefas da própria vida, assumindo toda a responsabilidade pelas consequências de ter investido a confiança nesse e não em qualquer outro exemplo.

Nos contornos institucionais da condução da experiência cotidiana, observa-se a destruição das pontes entre a vida privada e a vida pública ${ }^{5}$ que, se preservadas, ligariam

\footnotetext{
${ }^{5}$ Ver Bauman (2000), "Introdução" de Em busca da política.
} 
os sofrimentos individuais às demandas da agregação solidária personificada nos líderes. Desse ponto de vista, a "política da vida" é um terreno de reversão das motivações e disposições individuais para a ação concertada com seus semelhantes. A sofisticação das escolhas e a ampliação dos estilos de vida - ainda que muitas barreiras tradicionais tenham sido ultrapassadas - não desembocam na "democratização da democracia”. Se as vias de comunicação política entre o público e o pessoal estão interrompidas, a privatização das preocupações existenciais gera apatia política e assim as aspirações de uma "boa sociedade", algo que só se pode viver junto com outros, perdem-se nas prateleiras dos supermercados e no aconselhamento dos especialistas para minorar as infelicidades particulares de toda ordem.

Sob essa ótica, a diversidade cultural e a proliferação das formas alternativas de vida não resultam nas pretensões uniformizadoras do espírito moderno com suas "causas comuns". A garantia da liberdade dos estilos de vida e dos particularismos se expressa como um olhar à distância sobre as opções e o destino do outro, em um respeito frio e desinteressado, apesar das adoções convictas na feira das identidades. A política daí derivada, sob o emblema da "liberdade, diversidade e tolerância" (Bauman, 1999, p. 289), tem sua contrapartida no mercado que prospera na suposta satisfação das marcas simbólicas e das necessidades associadas à escolha do estilo de vida. A proliferação das formas alternativas de vida é acompanhada pela dissipação do arrebatamento pela "unificação do gênero humano" e da sublevação pelo compartilhamento.

Assim, o "projeto reflexivo do eu", esse convite atraente e fundado na interrogação destradicionalizante dos estilos de vida, pode degenerar em egoísmo e desinteresse dos "autorrealizados", talentosos e cultivados pelos seus semelhantes. Giddens tem razão quando lamenta que ninguém mais lê Marcuse ou os demais autores que foram 
inspirados pelos acontecimentos da década de 1960 com suas revoltas contra as autoridades e instituições. Mas transporta as "cascas" daquela liberdade (e de suas lutas coletivas) para o momento presente e acaba por supor que a reflexividade contemporânea fornece as condições para que o trabalho se complete e o "miolo" mantenha tais linhas de continuidade. A contribuição de Bauman traz advertências que mostram que a liberdade dos estilos de vida não deve servir de charme irresistível de uma individuação que prescinde da solidariedade e não interpela de forma enérgica os novos poderes constituídos.

O cosmopolitismo apreciado por Giddens está ancorado em forças que emergem por condições socialmente favoráveis ao autorreconhecimento e à autorrealização, fonte revigorada da solidariedade social, da mudança e da ampliação da democracia. Mas a dinâmica da reflexividade não dissipa a intensa privatização das relações humanas 268 e das formas de convívio. O sociólogo norte-americano Craig Calhoun faz uma observação apropriada sobre o tema quando diz, em entrevista ao jornal Folha de S.Paulo, de 28 de outubro de 2010, que "o cosmopolitismo é fruto da estranha convergência do antiautoritarismo dos anos 60 com as ideias do austríaco Frederik von Hayek e do americano Milton Friedman sobre o livre-mercado". Calhoun comenta ironicamente que boa parte da população do planeta não pode se tornar cosmopolita porque é pobre.

A "política da vida" na era do desengajamento não revitaliza os anos 1960; a responsabilidade pelo fracasso em cada caso particular recai sobre os indivíduos. Os lances do jogo de "estar de pé" ou de "alcançar a felicidade" não contam com nenhum suporte extraindividual (as redes de proteção social sucessivamente desmanteladas pela "economia política da incerteza") e assim cada pessoa se torna um empresário solitário de sua "política da vida", assumindo todos os riscos se os esforços forem malsucedidos. Descendo 
do nível do "sistema" para a "sociedade", como mencionado anteriormente, não seria um exagero dizer que o neoliberalismo não é apenas um projeto para liberar as forças do mercado e expandir as trocas econômicas, mas também determina "maneiras de ser" marcadas pelo desinteresse público e que se retraem na política pela intensa privatização de todos os vínculos.

Os desejos de felicidade e de autorrealização em um contexto de isolamento ou de extrema individualização se transformam em "utopias privatizadas", carentes de vitalidade pública (Bauman, 2001, p. 63). Para Bauman (p. 12), ao contrário dos anos 1960, quando todas as contestações estavam na ordem do dia, a "política da vida" indica a "evidente escassez de pessoas que se disporiam a ser revolucionários”. O que está em jogo aqui não é o lamento da passividade política: a privatização das utopias revela os impedimentos ocasionados pelos novos arranjos institucionais sobre as motivações sociais de participar ou interferir na esfera pública.

A "política da vida" não basta para mudar de lugar ou reavivar potências daqueles posicionados nos lados mais fracos da mudança, aqueles desamparados pelo desmantelamento do Welfare State e atingidos pelos efeitos da "economia política da incerteza". De outro lado, maior atenção e monitoramento reflexivo das ações, indagação sobre a vida a ser vivida, democratização das emoções e, enfim, ampliação da liberdade de escolha dos estilos de vida não neutralizam os ônus sociais da fragmentação e da privatização da experiência.

As predisposições cognitivas facilitadas pela reflexividade ajudaram muita gente a reconhecer a natureza de seus desejos e buscar a autorrealização pessoal, se os meios estiverem disponíveis para fazê-lo. Porém não suplantaram a intensa privatização do espaço público e seus reflexos na agenda das liberdades e contestações buscadas com os outros. 
O "projeto reflexivo do eu" ainda está longe de trazer calor para o esfriamento das formas de convívio humano em configurações institucionais que isolam os indivíduos na busca de uma "sociedade boa".

\section{Luis Carlos Fridman}

é professor titular do Departamento de Sociologia da UFF, Rio de Janeiro.

\section{Bibliografia}

BAUMAN, Z. 1998. O mal-estar da pós-modernidade. Rio de Janeiro: Jorge Zahar Ed. . 1999a [1991]. Modernidade e ambivalência. Rio de Janeiro: Jorge

Zahar Ed. 1999b. Globalização - as consequências humanas. Rio de Janeiro:

Jorge Zahar Ed. . 2000. Em busca da política. Rio de Janeiro: Jorge Zahar Ed. . 2001. Modernidade líquida. Rio de Janeiro: Jorge Zahar Ed.

BERMAN, M. 1986. "Tudo o que é sólido desmancha no ar: Marx, modernismo e modernização". In: Tudo que é sólido desmancha no ar-A aventura da modernidade. São Paulo: Companhia das Letras.

CALHOUN, C. 2010. Entrevista. Folha de S.Paulo, 28 out.

FRIDMAN, L. C. 1999a. "Pós-modernidade, sociedade da imagem e sociedade do conhecimento”. História, Ciências e Saúde, v. 6, n. 2, Rio de Janeiro. . 1999b. "Globalização e refugo humano". Lua Nova, n. 46, São Paulo. 2000. Vertigens pós-modernas - configurações institucionais contemporâneas. Rio de Janeiro: Relume Dumará. 2003. O jardim de Marx - comunismo e teoria social contemporânea. Rio de Janeiro: Relume Dumará, GIDDENS, A. 1989. A constituição da sociedade. São Paulo: Martins Fontes. 1991. As consequências da modernidade. São Paulo: Ed. Unesp. . 1993. A transformação da intimidade-sexualidade, amor e erotismo nas sociedades modernas. São Paulo: Ed. Unesp. . 1996. Para além da esquerda e da direita. São Paulo: Ed. Unesp. . 1997. "A vida em uma sociedade pós-tradicional”. In: GIDDENS, A.;

BECK, U.; LASH, S. Modernização reflexiva. São Paulo: Ed. Unesp. . 2000a. A terceira via - reflexões sobre o impasse político atual e o futuro da social-democracia. Rio de Janeiro: Record. 
2000b. Mundo em descontrole - o que a globalização está fazendo de nós. Rio de Janeiro: Record.

2002 [1999]. Modernidade e identidade. Rio de Janeiro: Jorge Zahar Ed.

MARCUSE, H. 1979. A ideologia da sociedade industrial: o homem unidimensional. Rio de Janeiro: Zahar.

ROUDINESCO, E. 2010. Retorno à questão judaica. Rio de Janeiro: Jorge Zahar Ed.

SEN, A. 1992. "Comportamento econômico e sentimentos morais". Lua Nova, n. 25.

SENNETT, R. 1999. A corrosão do caráter-consequências pessoais do trabalho no novo capitalismo. Rio de Janeiro: Record. 2006. A cultura do novo capitalismo. Rio de Janeiro: Record. 


\section{PRÓXIMOS OU SEPARADOS? \\ IDEIAS DE GIDDENS E BAUMAN SOBRE AS MOTIVAÇÕES PARA A POLÍTICA}

\section{LUIS CARLOS FRIDMAN}

Resumo: $\mathrm{O}$ texto avalia as interpretações e diagnósticos de Anthony Giddens e Zygmunt Bauman acerca das repercussões da dinâmica social na modernidade avançada sobre as motivações dos indivíduos para a ação política. Examina o otimismo prudente de Anthony Giddens e a "privatização das utopias" nas elaborações de Zygmunt Bauman, e busca estabelecer vias de entendimento desses problemas.

Palavras-chave: Modernidade Avançada; Subjetividade; Política; Giddens; Bauman.

\section{NEXT OR SEPARATED? IDEAS OF GIDDENS AND BAUMAN ON THE MOTIVATION FOR THE POLICY}

Abstract: The paper assesses the interpretations and diagnostics of Anthony Giddens and Zygmunt Bauman on the repercussions of social dynamics in modernity advanced on the motivations of individuals for political action. Examines the cautious optimism of Anthony Giddens and the "privatization of utopias" in elaborations of Zygmunt Bauman, and seeks to establish ways of understanding these problems. Keywords: Advanced Modernity; Subjectivity; Politicy; Giddens; Bauman. 